\title{
Application of Evapoclimatonomy to Monthly Surface Water Balance Calculations at the HAPEX-Sahel Supersites
}

\author{
José A. MARENGO* \\ Department of Meteorology, The Florida State University, Tallahassee, Florida \\ SHARON E. NICHOLSON \\ Department of Meteorology, The Florida State University, Tallahassee, Florida \\ ANDREW R. LARE \\ Applied Research Corporation, NASA/GSFC, Greenbelt, Maryland \\ Bruno A. Monteny and Sylvie Galle \\ ORSTOM, Laboratorie D'Hydrologie, Montpellier, France
}

(Manuscript received 19 December 1994, in final form 5 July 1995)

ABSTRACT

\begin{abstract}
In this paper a revised version of Lettau's evapoclimatonomy model is used to simulate climate in West Africa. The model is applied specifically to the study sites of the HAPEX-Sahel region in Niger, an international regional experiment to study regional-scale hydrological and energy balances of the Sahel. The model uses monthly means of precipitation, potential evapotranspiration, and solar radiation from the HAPEX-Sahel observations, as well as vegetation and soil parameters adequate for the region. Evapotranspiration, runoff, and soil moisture are determined. Differences are observed between the three vegetation types (guiera, grass, and millet) and between the three supersites.
\end{abstract}

\section{Introduction}

In hydrological modeling, a correct description of the energy and water exchanges at the land surface is of primary importance in regions where the only water supply is from rainfall, such as the Sahelian region in West Africa. The level of complexity of the parameterization of soil-vegetation-atmosphere exchanges depends on the final objective for modeling. If the water balance of the unsaturated soil is of interest, a correct knowledge of rainfall is no longer enough and one must take into account a more complex scheme for simulation of the land surface-atmosphere system, with emphasis on evapotranspiration and runoff. A host of studies (e.g., Charney 1975; Nicholson 1986, 1989; Entekhabi et al. 1992)

\footnotetext{
* Current affiliation: Centro de Previsão de Tempo e Estudos Climaticos, Instituto Nacional de Pesquisas Espaçiais, Sao Paulo, Brasil.
}

Corresponding author address: Dr. Sharon E. Nicholson, Department of Meteorology, B-161, The Florida State University, Tallahassee, FL 32306-3034. have supported the hypothesis that a feedback between the atmosphere and surface hydrology plays a role in drought in the Sahel region, hence, modeling of energy and water exchanges there can be of paramount importance.

The main objective of this study is to evaluate regional-scale water balance in the Sahel. A revised version of Lettau's evapoclimatonomy model (e.g., Lettau and Lettau 1969, 1975; Lare and Nicholson 1994) is applied to this problem. This work is done in the framework of the HAPEX-Sahel (Hydrologic and Atmospheric Pilot Experiment in the Sahel) project, a regional hydrology experiment carried out in 1991-92. It combined remote sensing and ground-based measurements with modeling efforts in order to study landatmosphere interaction in a large area of the Sahel (Wallace et al. 1994; Goutorbe et al. 1994; Prince et al. 1995). The measurements were taken in three "supersites" (southern-SS; central east-CE; and central west $-\mathrm{CW}$ ), all located in a $1^{\circ} \times 1^{\circ}$ square in Niger, West Africa (Fig. 1). We have implemented the evapoclimatonomy model over the experimental domain.

The details of the model are described in a companion paper (Nicholson et al. 1996a). In this paper the 


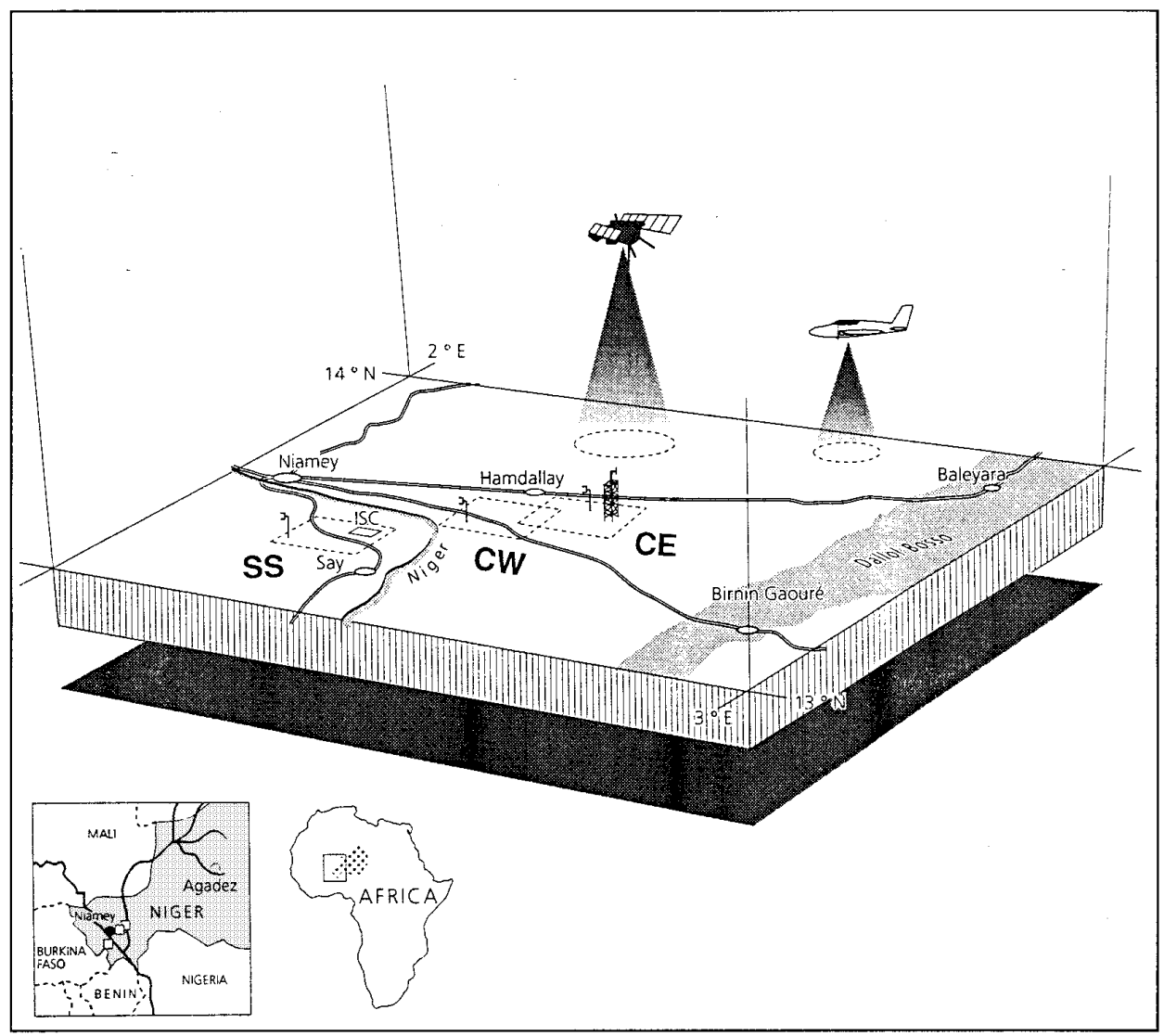

FIG. 1. Diagram showing the position of the HAPEX-Sahel experimental square and the three supersites (modified from Goutorbe et al. 1994). CE, CW, and SS indicate the position of the central east, central west, and southern supersite, respectively.

HAPEX-Sahel observations are utilized to show how this model, which includes a water balance scheme that takes into account atmospheric forcing, may be transformed to monitor soil moisture, evapotranspiration, and runoff at monthly scales. The model is applied to the three supersites and to the three vegetation types within them (fallow guiera, grass, and millet). In addition, we assess the sensitivity of soil moisture and evapotranspiration to potential evapotranspiration, rainfall, and vegetation cover. This complements an earlier study (Nicholson and Lare 1990) on model sensitivity to climatic input variables. The reader is also referred to Nicholson et al. (1996b), where a modified version is used to derive water balance components at daily scales during the intensive observational period, IOP (August-October 1992) of the HAPEX-Sahel experiment.

The evapoclimatonomy model has been applied before in studies of surface water balance in Africa (Nicholson and Lare 1990; Lare and Nicholson 1994; Farrar et al. 1994). However, comparative measurements for evaluating model output were not available. The data obtained during HAPEX-Sahel provide a unique opportunity for verification of the model.

\section{The Sahelian climate}

The Sahelian region occupies a narrow east-west band between the Sahara to the north and the Soudanian vegetation to the south, forming a strip about 400$600 \mathrm{~km}$ from north to south. The region is characterized by a single short rainy season associated with the northward migration of the intertropical convergence zone (ITCZ). The ITCZ represents the encounter of the dry, midcontinental air and the humid maritime air from the Atlantic that forms the ascending branch of the Hadley cell. Hot dry air from the Sahara is undercut by a wedge of cooler humid air from the Gulf of Guinea. Storms are generated by organized, easterly waves that propagate from east to west between the axis of the tropical easterly and the African easterly jets (Nicholson 1981, 1989). Local convective storms are also common, indicating that rainfall is highly variable in time and space. The ITCZ migrates north to south 
with the apparent movement of the sun so that rainfall decreases from south to north in the Sahel. The maximum northward extent of the ITCZ is reached in August, when maximum rainfall occurs (Ba et al. 1995).

The water balance of the Sahel is primarily a function of the precipitation and solar radiation regimes (Nicholson and Lare 1990). Mean annual rainfall ranges from $100 \mathrm{~mm}$ in the north to $800 \mathrm{~mm}$ in the south, with the peak of the rainy season concentrated from May to September (Nicholson 1981). The duration of the wet season decreases from about five months in the southern Sahel to three months in the north, with the annual rainfall being closely related to the duration of the rainy season. Potential evapotranspiration (Penman) is generally about $2000 \mathrm{~mm}$ (Sivakumar 1987). Virtually all drainage is endoreic and surface flow rarely occurs over more than a few hundred meters; ephemeral pools form during the rainy season and gradually evaporate between rain events (Peugeot and Esteves 1993).

Sahelian vegetation consists of annual grass and scattered bush steppe in the north, gradually merging into Soudanian savannas with perennial grasses, scattered trees, and extensive rain-fed cultivation in the south. The vegetation is strongly seasonal and virtually all woody species are deciduous (White 1983; Prince et al. 1994).

\section{Model overview}

The evapoclimatonomy model is essentially a numerical solution to the hydrologic balance equation. The model is forced by ground-absorbed solar radiation and rainfall; output consists of areally averaged soil moisture, evapotranspiration, and runoff (Fig. 2). Input variables, in addition to forcing functions, include sur- face and vegetation characteristics. The model includes two soil layers: a surface layer from 0 to $0.10 \mathrm{~m}$ and the bulk layer from 0 to $1.0 \mathrm{~m}$. The surface layer is assumed to determine the surface (immediate) runoff, while the bulk layer controls gravitational drainage. It is assumed that soil moisture exchange processes on the timescale of the model are confined to the $1.0-\mathrm{m}$ layer.

Two additional assumptions are made to keep the model simple (Lare and Nicholson 1990). First, runoff and evapotranspiration can be subdivided into immediate and delayed components, respectively, constituting processes that occur in the same month as the precipitation and those associated with rain that fell in previous months. Physically this separates temporal variations of runoff and evapotranspiration associated with superficial water from those utilizing subsurface moisture (Nicholson and Lare 1990). Second, the delayed processes are assumed proportional to soil moisture content.

An important model parameter is "residence time", $t^{*}$, a concept introduced to facilitate the solution of the model equation by creating a nondimensional timescale. It is the time required for a volume of water equal to the annual mean of exchangeable soil moisture to be depleted by the delayed processes of runoff and evapotranspiration. Residence time is calculated after Serafini and Sud (1987) as a function of potential evapotranspiration, the wilting point (the point at which the vegetation cannot absorb enough moisture to sustain itself and begins to wilt), and the maximum possible soil moisture storage.

A second parameter, which is empirically estimated, is termed "evaporivity" $e *$. This is defined as a nonlinear measure of the capacity of the land surface to use a portion of monthly solar radiation to evaporate

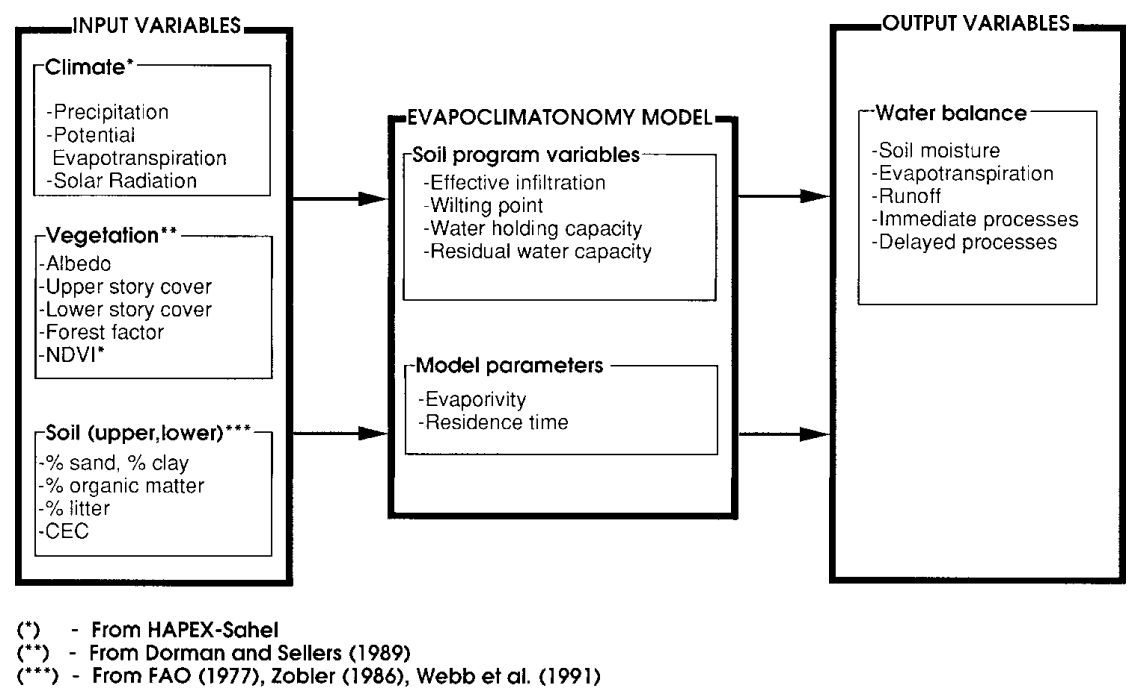

FIG. 2. Schematic of the evapoclimatonomy model. 
precipitation received in the same month (Lare 1992). It is analogous to potential evapotranspiration in that it governs the efficiency of evaporation by solar radiation, and its calculation is based on NDVI (Nicholson et al. 1996).

Model runoff is generated by gravitational drainage of soil water (a "delayed" process ) and surface runoff (an 'immediate", process) due to precipitation exceeding infiltration rate (Warrilow 1986). Gravitational drainage is a function of soil texture and moisture content in the bulk layer; infiltration rate is a function of soil texture in the surface layer. The parameterization of infiltration rate and hydraulic conductivity (Saxton et al. 1986) is based on frequency distributions of daily rainfall totals. A residual water capacity and a crusting parameter are also calculated (Rawls and Brakensiek 1989; and Brakensiek and Rawls 1983, respectively).

\section{Supersites and vegetation}

The experiment was set within a $100-\mathrm{km}$ square $\left(13^{\circ}-14^{\circ} \mathrm{N}, 2^{\circ}-3^{\circ} \mathrm{E}\right)$ in Niger, West Africa. Within this grid, three supersites were defined. The size of the supersites $\left(100-200 \mathrm{~km}^{2}\right)$ matches the scale at which the atmospheric boundary layer responds to changes in the land surface. Of the three supersites, the southern and central west sites were intended primarily for surface flux and energy balance studies, while the central east site was selected primarily as a catchment for hydrologic studies (Monteny 1993; Monteny et al. 1994; Prince et al. 1994).

Within these supersites four subsites were intensively monitored, each corresponding to one of four principal vegetation types in the region: tiger bush, fallow grass, fallow guiera (all three natural vegetation), and millet, the staple cereal crop of the Sahel. The guiera is a typical wooded savanna, with a grass understory and relatively little exposed soil. The millet plants are typically $1-2 \mathrm{~m}$ high and are sown at intervals on the order of $1 \mathrm{~m}$; thus, considerable bare soil is exposed, and evaporation from the soil surface can be a significant component of the total evapotranspiration, particularly just after rainfall. The grass cover is 10$20 \mathrm{~cm}$, with about $65 \%$ cover. The tiger bush formation is one in which vegetation grows in dense clusters, surrounded by large meandering areas of bare ground. Because of the complexity of modeling this site and the lack of understanding of the reason for this particular growth pattern, the climatonomy model will not be applied to this formation.

\section{Climate, soil, and vegetation during HAPEX- Sahel}

\section{a. Climatic variables}

Rainfall was measured with the EPSAT-Niger network of 100 recording rain gauges for the three super- sites. Beyond the limits of the gauge network study area, a weather radar system (ECCWR 100-5 type) provided an extensive spatial coverage as far as 350 $\mathrm{km}$ (Lebel et al. 1992). The first results of the EPSATNiger have shown that the spatial variability of rainfall is very large at all timescales (Lebel et al. 1995a,b; Lebel and LeBarbe 1995). The largest spatial gradient in rainfall was observed over the Southern supersite, while over the central east and west supersites rainfall distribution is more homogeneous. Rainfall data from the three supersites were kindly provided by T. Lebel (ORSTOM, France) and the EPSAT-Niger team. In order to obtain rainfall representative of each supersite, values from seven stations located in each supersite were averaged inside the domain for each supersite: $\mathrm{CE}\left(13.687^{\circ}-13.812^{\circ} \mathrm{N}, 2.5^{\circ}-2.75^{\circ} \mathrm{E}\right), \mathrm{CW}$ $\left(13.5^{\circ}-13.75^{\circ} \mathrm{N}, 2.687^{\circ}-2.937^{\circ} \mathrm{E}\right)$, and SS $\left(13.125^{\circ}-\right.$ $13.250^{\circ} \mathrm{N}, 2.125^{\circ}-2.25^{\circ} \mathrm{E}$ ). See map in Fig. 1 for the supersites location.

Lebel et al. (1992) have indicated strong spatial gradients of rainfall near the SS supersite during the 1992 experimental year, with a maximum of $782 \mathrm{~mm}$ and a minimum of $507 \mathrm{~mm}$ over a distance of only $9 \mathrm{~km}$. Over the central sites, rainfall distribution was somewhat homogeneous. On average, the central east and west sites received 424 and $520 \mathrm{~mm}$, respectively, while the southern site received $606 \mathrm{~mm}$ during 1992.

Daily climatological quantities and fluxes were obtained primarily for the CE supersite and were provided by B. Monteny (ORSTOM, France). Hydrological measurements and heat fluxes over both bare soils and vegetated surfaces were measured for each of the major land-use types at each supersite, using micrometeorological techniques to give averages at the field scale (Monteny 1993). These observations include global radiation at the surface and are to be used mostly to provide a set of initial conditions that serve as input variables for the evapoclimatonomy model runs.

Extensive networks were set up for monitoring soil moisture primarily for the CE and SS supersites. Volumetric water content measurements were made for tiger bush and millet at the central east supersite and for fallow guiera, millet, and tiger bush for the southern site. For the purposes of this work, we will not include tiger bush in our analysis. Soil moisture measurements were taken at intervals of 1-7 days at given depths and transects and were provided by J. D. Cooper (Institute of Hydrology, United Kingdom), and S. Galle (ORSTOM, France). Soil moisture was measured using neutron probes (Gardner et al. 1991). Measurements from all observation layers from the surface to $1.00 \mathrm{~m}$ were integrated to validate the soil moisture estimated by the evapoclimatonomy model. To validate our model, we used the average measurements of between 7 and 10 probes at each site. The model uses soil information integrated over the top $0.10 \mathrm{~m}$ and over the top $1.00 \mathrm{~m}$, and since the model uses integrated infor- 
TABLE 1. Summary of soil properties for the HAPEX-Sahel domain. This information is from FAO (1977), FAO/UNESCO (1971-87), Zobler (1986), and Webb et al. (1991) and is based on FAO's soil classification. Upper-layer of the soil is between 0 and $0.1 \mathrm{~m}$ and the bulk-layer is $0-1.00 \mathrm{~m}$. Measurements are from B. Monteny for the fallow guiera field at the CE site, organic matter, and cation exchange capacity were not available from these observations.

\begin{tabular}{lcc}
\hline \hline \multicolumn{1}{c}{ Soil type } & $\begin{array}{c}\text { Monteny } \\
\text { (measurement) }\end{array}$ & $\begin{array}{c}\text { FAO } \\
\text { QL (Luvic arenosol) }\end{array}$ \\
\hline Percent sand & & \\
Upper layer & 91.0 & 93.0 \\
Bulk layer & 88.7 & 88.6 \\
Percent clay & & \\
Upper layer & 4.9 & 5.7 \\
Bulk layer & 9.0 & 8.4 \\
Percent organic matter & & 0.3 \\
Upper layer & - & 0.3 \\
Bulk layer & - & 7.4 \\
Cation exchange capacity & & 0.5 \\
$\quad$ Upper layer & - & \\
Bulk layer & - & \\
\hline
\end{tabular}

mation to describe a 1.00-m layer, the observations must also be integrated for the same $1.00-\mathrm{m}$ layer.

\section{b. Soil and vegetation}

Vegetation data were used as input to the model, including surface albedo and NDVI. NDVI (Justice 1986 ) is calculated using global area coverage (GAC) data from the Advanced Very High Resolution Radiometer (AVHRR) carried on NOAA meteorological polar-orbiting satellites for the $50 \times 50$ quadrants of the $1^{\circ} \times 1^{\circ}$ region (Justice et al. 1986). Albedo and other vegetation parameters necessary to force the model were obtained from other sources since no observations of these parameters were available. Surface albedo was taken from global monthly fields derived by Dorman and Sellers (1989) on the basis of vegetation type. Although the grid for these is coarse $\left(4^{\circ}\right.$ $\times 5^{\circ}$ ), sensitivity studies run on the model indicate that errors as large as $50 \%$ resulted in soil moisture differences of less than 9\% (Nicholson and Lare 1990). Other vegetation parameters such as the upper and lower story vegetation cover and the emissivity were taken from Dorman and Sellers (1989) and Stull (1988), respectively.

Information on soil texture and particle size were obtained from Zobler (1986) and Webb et al. (1991) for the $1^{\circ} \times 1^{\circ}$ grid box that comprises the HAPEXSahel domain. Soil type was derived from the FAO soil map of the World (FAO/UNESCO, 1971-87). Table 1 shows the soil information for the HAPEX-Sahel domain required to run the model, as given by FAO. For comparison, Table 1 also gives soil information obtained from samples taken at the savanna fallow guiera site of the CE supersite (Monteny 1995, personnal communication).

\section{Methodology}

The revised version of the evapoclimatonomy model was run for the three HAPEX-Sahel supersites. Model input included global solar radiation at surface, potential evapotranspiration, precipitation, NDVI, and albedo, as well as vegetation and soil parameters (Table 2 ). Precipitation at each supersite was obtained as the average of seven stations within the supersites. Since potential evapotranspiration and solar radiation are available only for the $\mathrm{CE}$ site, we are assuming that those climatic observations are representative for all

TABLE 2. Forcing and input to the evapoclimatonomy model: $P$ - precipitation (mm), PET — potential evapotranspiration (mm), and SR — global solar radiation at surface (MJ m ${ }^{-2}$ ) are from the HAPEX-Sahel database campaign 1992. NDVI is given for fallow guiera (FGA), fallow grass (GRS), and millet (MIL). Average precipitation ( $P$-average) was from seven stations located at each supersite. For the SS supersite, average rainfall for the guiera and millet is from three stations located inside the respective local fields. PET is for Niamey, as estimated from Penman's method for the period 1953-62 (Wallace et al. 1994).

\begin{tabular}{|c|c|c|c|c|c|c|c|c|c|c|c|c|c|}
\hline Variable & $\mathbf{J}$ & $\mathrm{F}$ & $\mathrm{M}$ & $\mathrm{A}$ & M & $\mathbf{J}$ & $\mathrm{J}$ & $\mathrm{A}$ & $\mathrm{S}$ & $\mathrm{O}$ & $\mathrm{N}$ & $\mathrm{D}$ & Ann \\
\hline SR & 18.5 & 22.7 & 19.3 & 23.3 & 23.9 & 23.7 & 20.9 & 21.3 & 22.8 & 23.1 & 20.1 & 20.5 & 21.7 \\
\hline PET & 161 & 167 & 207 & 209 & 219 & 203 & 156 & 131 & 137 & 171 & 158 & 143 & 2057 \\
\hline NDVI FGA & 0 & 0 & 0 & 0 & 0 & 0 & 0.04 & 0.12 & 0.16 & 0.17 & 0.10 & 0.04 & \\
\hline NDVI GRS & 0 & 0 & 0 & 0 & 0 & 0 & 0 & 0.08 & 0.15 & 0.20 & 0.10 & 0.05 & \\
\hline NDVI MIL & 0 & 0 & 0 & 0 & 0 & 0 & 0 & 0.04 & 0.12 & 0.05 & 0 & 0 & \\
\hline \multicolumn{14}{|l|}{ CE supersite } \\
\hline$P$-average & 0 & 0 & 0 & 0 & 4 & 39 & 109 & 207 & 65 & 0 & 0 & 0 & 424 \\
\hline \multicolumn{14}{|l|}{$\mathrm{CW}$ supersite } \\
\hline$P$-average & 0 & 0 & 0 & 0 & 10 & 54 & 151 & 226 & 76 & 3 & 0 & 0 & 520 \\
\hline \multicolumn{14}{|l|}{ SS supersite } \\
\hline$P$-average & 0 & 0 & 0 & 12 & 44 & 93 & 166 & 229 & 63 & 0 & 0 & 0 & 606 \\
\hline$P$-millet field & 0 & 0 & 0 & 11 & 51 & 79 & 171 & 204 & 63 & 0 & 0 & 0 & 576 \\
\hline$P$-guiera field & 0 & 0 & 0 & 13 & 43 & 99 & 150 & 315 & 86 & 0 & 0 & 0 & 708 \\
\hline
\end{tabular}


three supersites. Surface albedo and NDVI are available for each vegetation type in the three supersites, which allows the application of the water balance model for individual vegetation types at a particular supersite. Table 2 contains the climatic observations indicated above, as well as the NDVI values for guiera, grass, and millet.

Rainfall reaches a maximum in August and remains near zero from October to April at the $\mathrm{CE}$ and $\mathrm{CW}$ supersites (October to March at the SS supersite). Solar radiation and evapotranspiration reach a maximum prior to the rainy season and are lowest during the dry season with a secondary minimum occurring during the heart of the rainy season (July and August).

Soil moisture estimates for the three-month period August through October 1992 will be compared with observations in the SS supersite (millet and fallow guiera). They represent the average of the days with observations in each of the three months measurements and were obtained from eight neutron probe tubes installed at the millet fields and seven installed in the fallow guiera field for the SS.

The runs have been made assuming that precipitation averaged for each of the three supersites is representative of all local fields within. In addition, for the SS supersite, the model has been run with rainfall averaged for the guiera and millet fields, specifically.

\section{Model results of water balance at the three supersites}

Model output consists of soil moisture, total evapotranspiration, and total runoff, as well as immediate and delayed evapotranspiration and runoff parameters. The basic results are illustrated in Figs. $3 \mathrm{a}-\mathrm{c}$ for the millet fields at each supersite; general aspects of these results are similar for the other fields. The most obvious characteristics of the water balance are that most of the rainfall is balanced by evapotranspiration rather than runoff; that evapotranspiration peaks in August, concurrent with peak rainfall; and that soil moisture peaks in September. During the rainy season evapotranspiration ranges from about $50 \mathrm{~mm}$ per month at the onset and end to peak values of nearly $200 \mathrm{~mm}$ per month. These results suggest that evapotranspiration totals about $90 \%-95 \%$ of annual rainfall; runoff is small and is limited to August.

Several aspects of the region's climatology support the validity of these results. Both Henning (1989) and Albrecht (1965) estimate annual evapotranspiration in the Sahel to be about $500 \mathrm{~mm}$, close to the model calculations of roughly $500 \mathrm{~mm}$. The evaporation ratio for the region (Sellers 1965 ) should be on the order of $0.9-$ 0.97 , which would correspond to runoff on the order of $6-30 \mathrm{~mm}$ per year. The low amount of runoff is consistent with Niger River hydrology, the lack of flow increase as the river passes between Dire and Niamey (Entekhabi 1984). It is also consistent with the fact that
WATER BALANCE
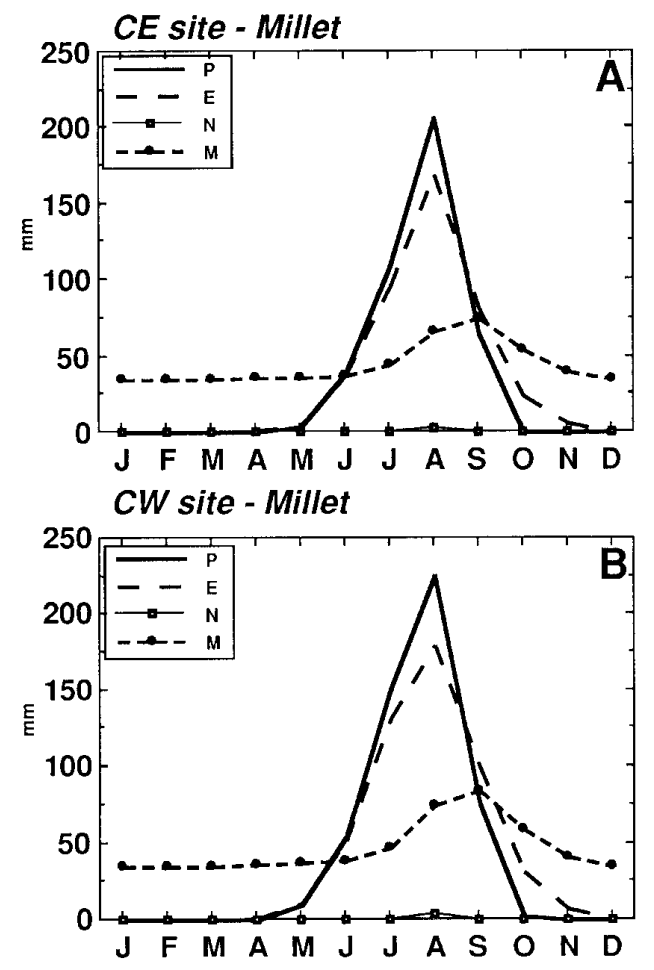

SS site - Millet

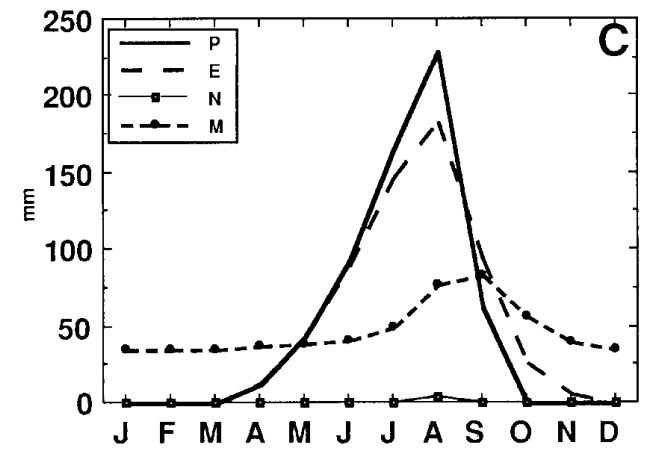

FIG. 3. Modeled monthly water balance for millet in the HAPEXSahel supersites; $P$ denotes precipitation; $E$ denotes evapotranspiration; $M$ denotes soil moisture; and $N$ denotes runoff. (a) Central east supersite; (b) central west supersite; (c) southern supersite. Units are millimeters.

most of the water that runs off forms small pools, which eventually evaporate and contribute to the evaporative portion of the annual water balance.

Figures $4 \mathrm{a}-\mathrm{c}$ shows the partitioning of evapotranspiration into immediate $\left(E^{\prime}\right)$ and delayed processes $\left(E^{\prime \prime}\right)$. The immediate process $E^{\prime}$ is primarily the result of ground evaporation from soil and the evaporation from the water collected in surface depressions. It peaks in August, along with rainfall, but it is also high in July at the CE and SS supersites, which experienced rela- 
IMMEDIATE AND DELAYED EVAPOTRANSPIRATION
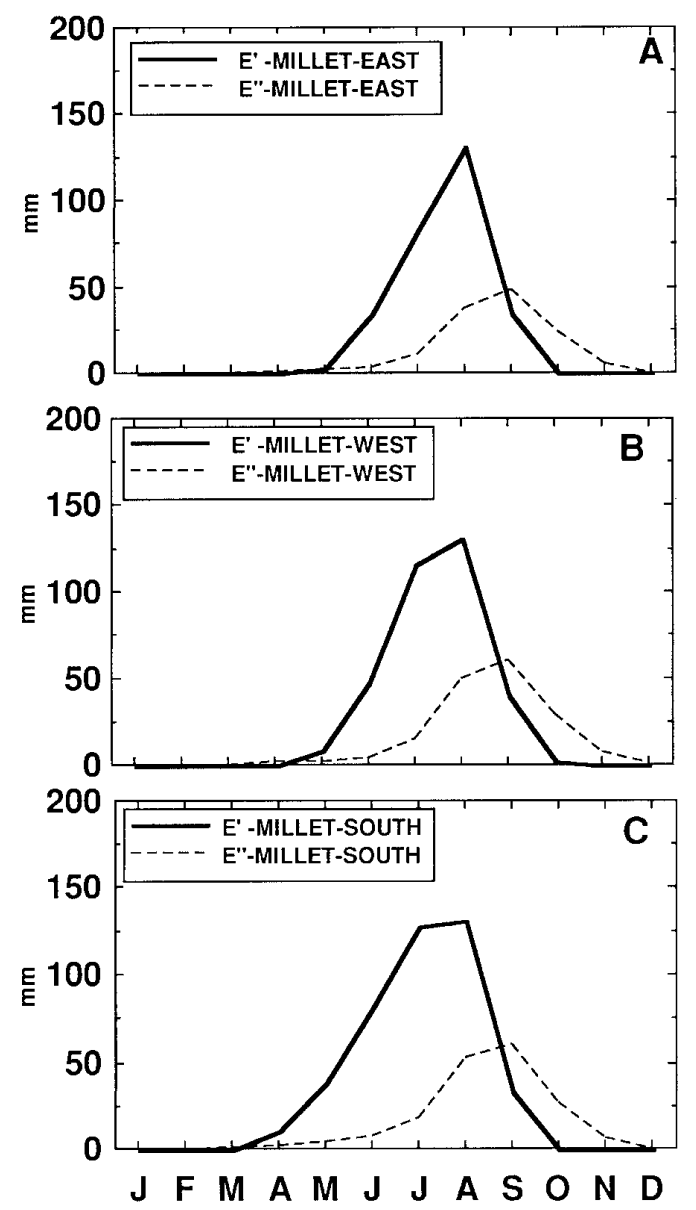

FIG. 4. Immediate $\left(E^{\prime}\right)$ and delayed $\left(E^{\prime \prime}\right)$ evapotranspiration for millet. (a) Central east supersite; (b) central west supersite; (c) southern supersite. Units are millimeters.

tively high rainfall in July (Table 2 ). The delayed process $E^{\prime \prime}$, which is mostly transpiration by plants plus some evaporation of soil moisture from deeper layers, peaks in September in all cases, along with soil moisture, but it is also high in August. The delayed process is on the order of 1-2 $\mathrm{mm}$ per day during these months, roughly in agreement with measurements of Wallace et al. (1994), giving 2-3 $\mathrm{mm}$ per day for the SS supersite. Overall, most of the evaporation, about $70 \%$, is immediate. It exceeds delayed evapotranspiration early in the season (i.e., between April and August) before the rainfall could be fully incorporated by plants (Lare 1992). Evaporation is also more efficient at this time (evaporivity varies from 0.6 to 0.8 , compared to 0.5 during August). Delayed evapotranspiration exceeds immediate when the surface begins to dry out and rainfall ceases, but plants draw moisture from deeper soil layers. This is the case from September until December, when evapotranspiration ceases.
The differences among sites and vegetation covers is illustrated in Figs. 5a-i, which presents evapotranspiration, soil moisture, and runoff for each local field at each supersite. In this case, rainfall used to run the model was a supersite average, so differences among local vegetation fields do not reflect differences in rainfall. The greatest differences are apparent in soil moisture, which varies by $10 \%-15 \%$ between supersites and up to $10 \%$ between vegetation types within them.

Among the three vegetation types, evapotranspiration increases more slowly at the guiera sites than at grass and miller sites, showing a distinct August peak, rather than a broad July-August maximum; it is also generally somewhat lower for guiera. This translates to higher soil moisture for the guiera sites, especially during July and August, with differences of 10 or $20 \mathrm{~mm}$. The earlier increase of evapotranspiration for grass and millet is physically realistic, as these are shallow-rooted plants that can utilize the early rainfall stored in the upper soil layers. There is little difference in runoff among the local vegetation sites or the supersites. This result is probably not realistic. It likely results from the greater sensitivity of the runoff parameterization to soil texture, which is similar at all sites, than to vegetation.

Consistent differences in model-calculated evapotranspiration and soil moisture are evident among the three supersites. Overall, both evapotranspiration and soil moisture are lowest at the CE supersite and highest at the SS supersite. The contrast in evapotranspiration between the Southern supersite and the others is greatest early in the rainy season; at that time, evapotranspiration varies by up to $40 \mathrm{~mm}$ between the supersites. This clearly reflects differences in rainfall, particularly the higher totals at the southern supersite in May and June. The relatively low rainfall at the CE supersite in July is also reflected as lower evapotranspiration there compared to the other supersites. Differences in evapotranspiration are minimal starting in August, from which time rainfall totals were comparable at all three supersites. In contrast, variation in soil moisture among the supersites reached a maximum in August and September, when it is $10-30 \mathrm{~mm}$ greater at the SS and CW than at the CE supersite. The lower soil moisture and lower evapotranspiration at the CE site is confirmed via analysis of the Bowen ratios (sensible to latent heat) for the three supersites during the IOP, as presented by Goutorbe et al. (1994). Ratios are higher at the CE site.

The validity of these results is assessed via a comparison with soil moisture measurements made during HAPEX-Sahel. Sufficient soil moisture measurements for temporal continuity and vertical integrations are available only for the southern supersite and only for millet and guiera. This comparison is rendered difficult by the high spatial variability of rainfall in the region, which is particularly high at the southern supersite (Lebel et al. 1992). Although rainfall was measured at numerous locations within each supersite, the number of rain gauges for each local field (i.e., vegetation type) 


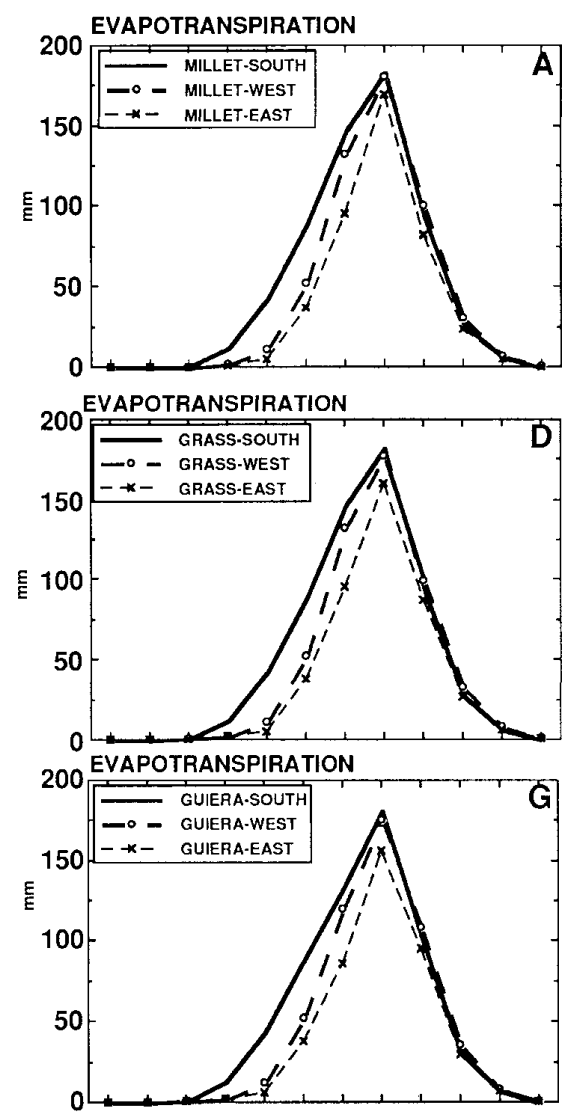

SOIL MOISTURE

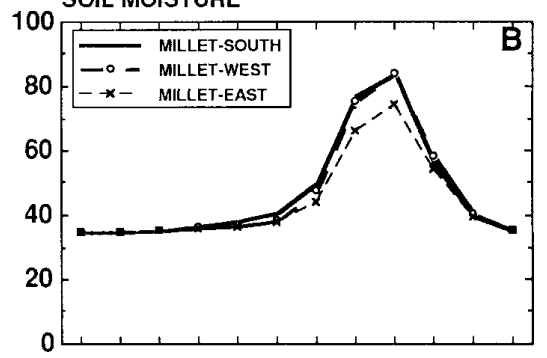

SOIL MOISTURE
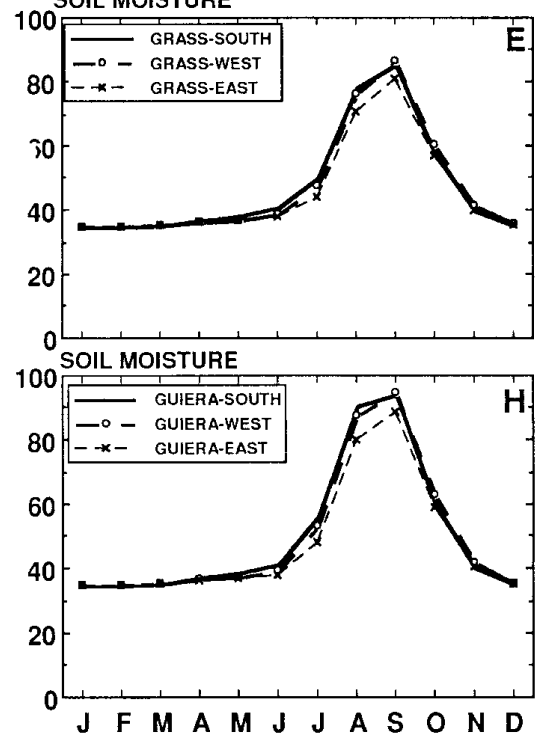

RUNOFF

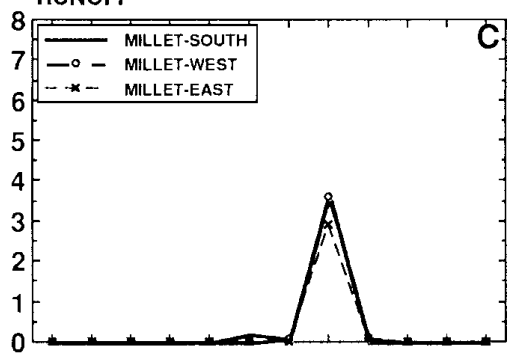

RUNOFF

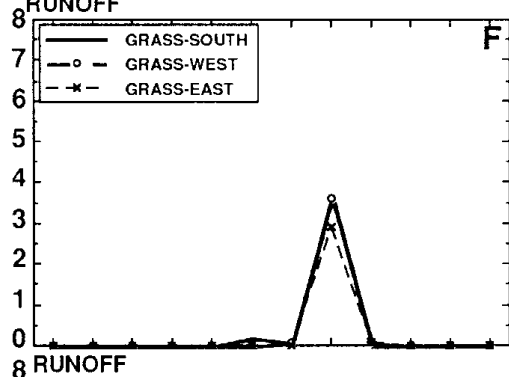

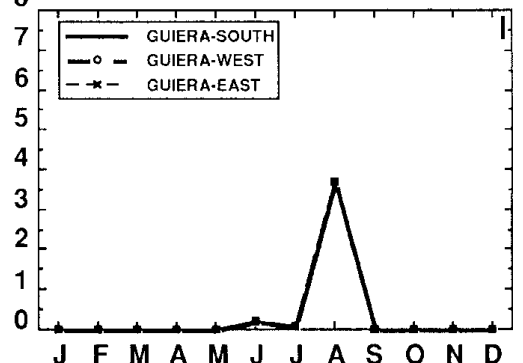

FIG. 5. Modeled evapotranspiration $E$, soil moisture $M$, and runoff $N$ for the three supersites and the vegetation types: millet (a), (b), (c); grass (d), (e), (f); guiera (g), (h), (i). Units are millimeters.

is limited. Thus, the question arises as to whether or not the model should be run with data averaged for the local field or the entire supersite. We chose to do both runs for the comparison with soil moisture measurements. The variation in rainfall among the local fields is shown in Table 2 . The guiera field received almost $15 \%$ more than the average for the supersite, the millet field about $5 \%$ less. For the year as a whole, the guiera field received $132 \mathrm{~mm}$ more than the millet field and $111 \mathrm{~mm}$ more in August alone.
Table 3 shows calculated and measured soil moisture for the months of August-October for both millet and guiera. The measurement represents an integral of the 1.0-m layer of soil, which the model-calculated soil moisture is assumed to represent. Agreement is excellent for the millet field: when the model is forced with average rainfall for the supersite, the difference between measured and calculated soil moisture is about $4 \mathrm{~mm}$ in the months of August and September, when observed soil moisture is about $80 \mathrm{~mm}$. Differences are

TABLE 3. Comparisons between modeled and observed soil moisture for the SS supersite. Observations are from HAPEX-Sahel and were integrated for the 100-cm layer by using neutron probes at 10-, 20-, 25-, 30-, 40-, 60-, 80-, and 100-cm depth (available for AugustSeptember 1992 only). One asterisk indicates that the model was run with rainfall averaged at a supersite scale (seven stations per supersite); two asterisks indicate that the model was run with rainfall for stations inside the local field (three stations inside the local field). Units are millimeters.

\begin{tabular}{|c|c|c|c|c|c|c|}
\hline & \multicolumn{3}{|c|}{ Millet, SS } & \multicolumn{3}{|c|}{ Fallow guiera, SS } \\
\hline & Model* & Model** & Observations & Model* & Model** & Observations \\
\hline August & 77.6 & 70.5 & 81.8 & 90.6 & 108.1 & 111.9 \\
\hline September & 83.9 & 74.6 & 79.9 & 94.2 & 121.8 & 100.7 \\
\hline October & 56.4 & 54.0 & 47.5 & 60.1 & 70.9 & 56.2 \\
\hline
\end{tabular}


SENSITIVITY TO PRECIPITATION

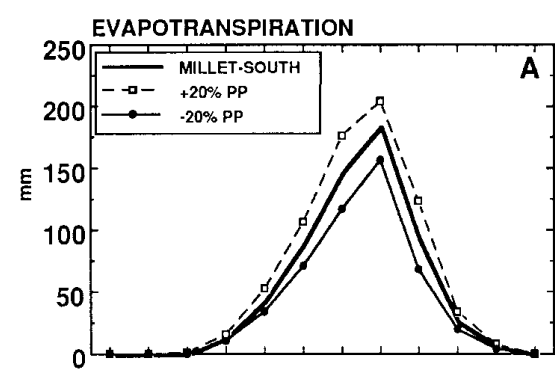

SOIL MOISTURE
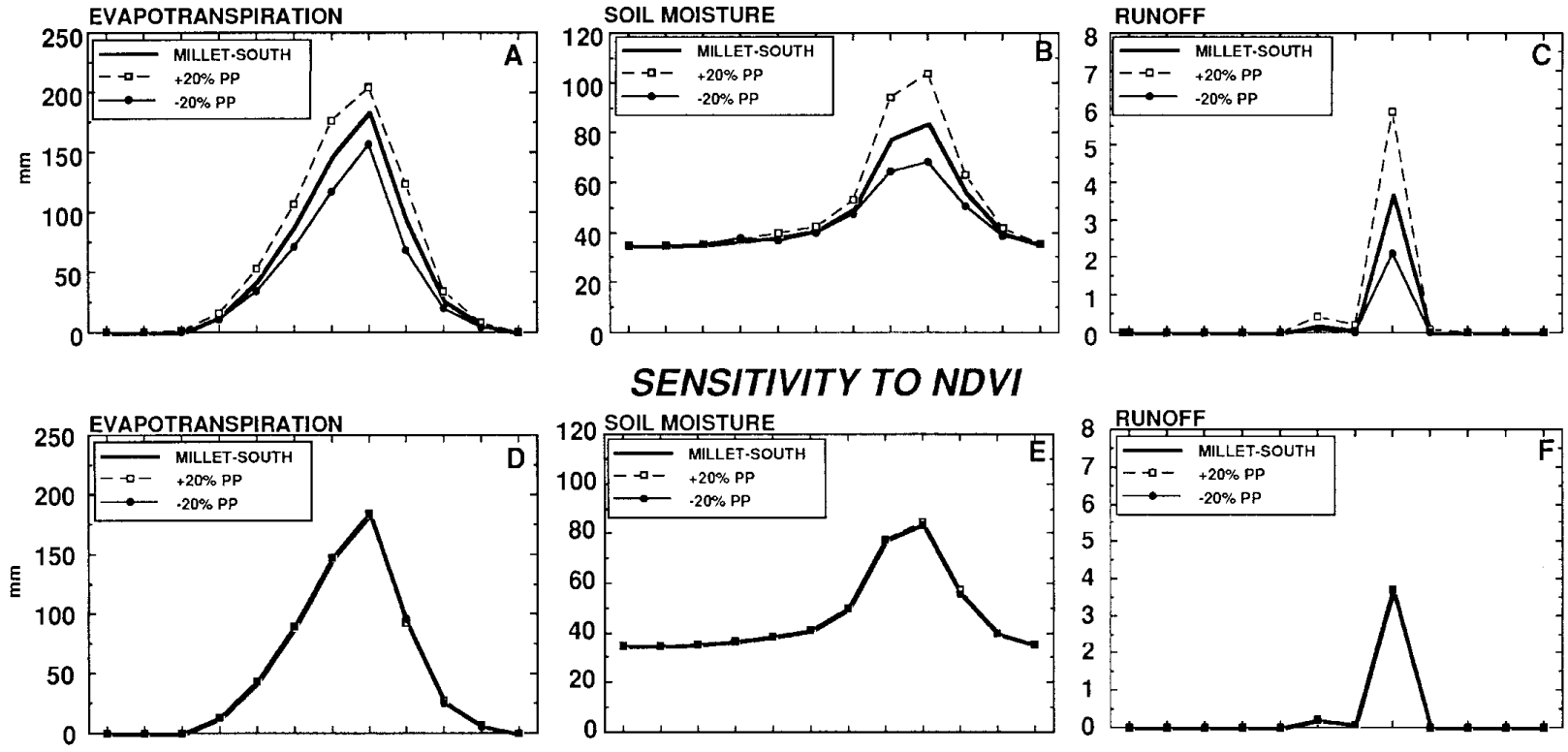

SENSITIVITY TO NDVI
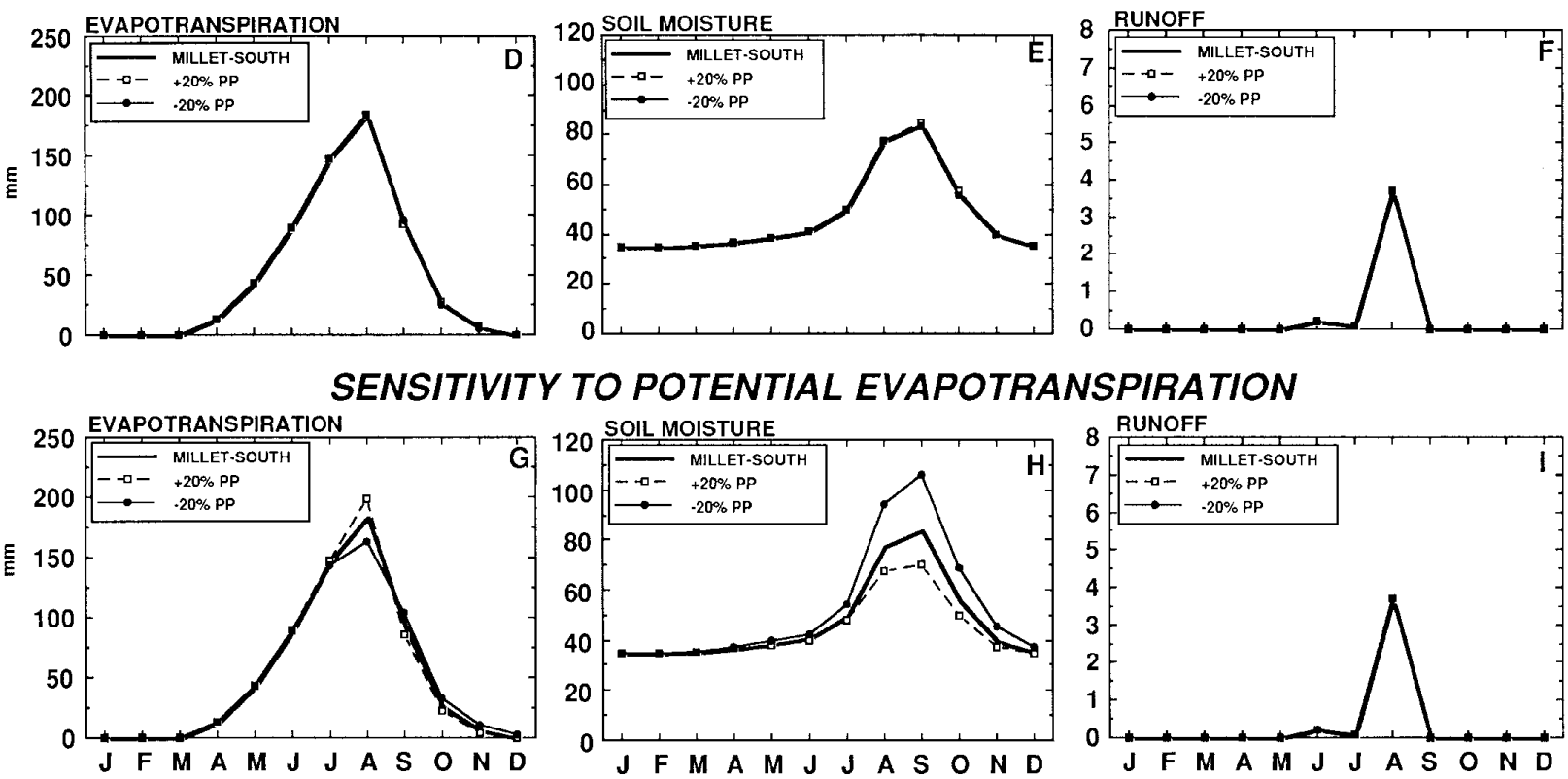

FIG. 6. Sensitivity of the evapoclimatonomy model to changes of $\pm 20 \%$ in precipitation (a), (b), (c), NDVI (d), (e), (f) and potential evapotranspiration (g), (h), (i). Variations in evapotranspiration, soil moisture, and runoff have been assessed for millet at the southern supersite. Units are millimeters.

slightly larger when rainfall for the local field forces the model. For October, with observed soil moisture of $48 \mathrm{~mm}$, differences between calculated and measured soil moisture are 6 and $8 \mathrm{~mm}$ for model runs forced with local and supersite-averaged rainfall, respectively.

The results for guiera compare somewhat less favorably with measurements, but the model correctly predicts considerably higher soil moisture at this field than at the millet field. For guiera, there is a distinct soil moisture maximum in August, while the model predicts it for September. Magnitudes compare more favorably. Measured soil moisture is 112 and $101 \mathrm{~mm}$, respectively, for August and September; the August calculations are 91 and $108 \mathrm{~mm}$ for supersite and local rainfall, respectively, while those for September are 94 and $122 \mathrm{~mm}$, respectively. Overall, the results of model runs using local rainfall do not show better agreement with measured soil moisture than those using supersite averages.

\section{Sensitivity analysis}

We have tested the sensitivity of the evapoclimatonomy model to changes in three primary input parameters. Precipitation, NDVI, and potential evapotranspiration were each varied by $+20 \%$, holding other parameters constant. The sensitivity of total evapotranspiration, soil moisture storage, and runoff to these parameters was assessed. Because the results were similar at all three supersites, here we present only the sensitivity studies for the millet field at the SS supersite.

All three water-balance parameters show sensitivity to precipitation during the three or four wettest months. A $20 \%$ increase in precipitation increases evapotranspiration and soil moisture about $15 \%$ and $28 \%$, respectively, during the wet season (Figs. 6a,b), while runoff increases by almost $50 \%$ (Fig. 6c). Evapotranspiration is reduced by about the same amount when rainfall is reduced by $20 \%$, but soil moisture and runoff are some- 
what less sensitive to a $20 \%$ reduction in precipitation than to a $20 \%$ increase.

A 20\% change in NDVI has no effect on either evapotranspiration, soil moisture, or total runoff (Figs. $6 \mathrm{~d}-\mathrm{f}$ ) or their seasonal cycles. The lack of sensitivity to this parameter may underscore the need for explicit parameterization of vegetation in the model.

The sensitivity of the model to potential evapotranspiration is shown in Figs. 6g-i. A 20\% increase in potential evapotranspiration increases evapotranspiration by about $6 \%$ during the wet season and reduces soil moisture by $18 \%$ during this period but has little effect on runoff. In contrast, an equivalent decrease in potential evapotranspiration reduces evapotranspiration by the same amount but increases soil moisture by about $27 \%$ during the wettest months, with no apparent effect on runoff.

These results indicate that model results are sensitive to both precipitation and potential evapotranspiration, but the two variables influence the water balance in different ways. Both have a considerably greater influence on soil moisture than on evapotranspiration. An increase (decrease) in precipitation increases (decreases) both evapotranspiration and soil moisture. However, changes in potential evapotranspiration have opposite effects on evapotranspiration and soil moisture. Higher potential evapotranspiration increases evapotranspiration but reduces soil moisture. Overall, there is an asymmetric response of soil moisture to symmetric changes in precipitation and potential evapotranspiration. Based on the magnitude of the associated changes, our results suggest that although precipitation and potential evapotranspiration both influence the availability of soil moisture, rainfall is the main limiting factor in this environment.

\section{Summary and conclusions}

In the context of the HAPEX-Sahel regional experiment, the main objective of this paper was to study regional-scale hydrological water balances in the three supersites during 1992. With that purpose we have used a revised and more physically based version of Lettau's evapoclimatonomy model, which has been successfully applied to climate studies in West Africa (Lare and Nicholson 1990, 1994; Lare 1992). In this study, the forcing functions for the model were monthly precipitation, potential evapotranspiration, and incident solar radiation at the surface, as obtained from the HAPEXSahel dataset. Model calculations showed that evapotranspiration and soil moisture storage account for most of the precipitation.

Differences in rainfall at the three supersites result in differences in evapotranspiration and soil moisture at these sites. Soil moisture is highest at the SS supersite and lowest at the CE supersite. Among the three vegetation types, soil moisture at the millet is generally $15 \%-20 \%$ lower than at guiera sites in all cases. This may be due to lower water demand for guiera than for millet, as reflected in their respective evapotranspiration rates. Precipitation and evapotranspiration peak in August, one month before the peak in soil moisture. Evapotranspiration is dominated by immediate processes at all three supersites and for all three vegetation types, with the delayed component peaking in September, one month after the maximum in immediate evapotranspiration. Peak soil moisture values range from 70 to $100 \mathrm{~mm}$ for the different vegetation types, varying around $15 \%$ among the different supersites.

Evapotranspiration shows relatively little sensitivity to NDVI and potential evapotranspiration but strong sensitivity to rainfall. Changes in rainfall affect primarily soil moisture and runoff, while changes in potential evapotranspiration influence primarily soil moisture. Overall, the system is more sensitive to precipitation than to potential evapotranspiration, indicating that the former is the limiting factor in moisture availability.

Although the sensitivity studies show reasonably large changes in some variables, they also indicate the robustness of the model. A $20 \%$ change in rainfall is quite extreme, yet it modifies soil moisture by, at most, about $15 \%-20 \%$. The only result that is not physically realistic is the low sensitivity of evapotranspiration to NDVI. However, in the current version of the model, NDVI affects only "evaporivity" and thus only the partitioning of the delayed and immediate processes; its impact on radiation absorption, infiltration, etc., is not adequately modeled. More realistically, the vegetation is the main contributor to delayed evapotranspiration and a further model revision will be to incorporate NDVI into the calculation of delayed evapotranspiration.

The values of soil moisture storage calculated by the model are comparable to the measurements from the HAPEX-Sahel experiment. For the SS supersite (Table 3 ) the modeled and observed values differ by about $10 \%-15 \%$. The use of areally averaged rainfall for the entire supersite or rainfall from the local field does not significantly influence these differences. Modeled evapotranspiration oscillates between 500 and $600 \mathrm{~mm}$ per year and is thus close to the values reported by Sivakumar (1987), Henning (1989), and the Direction de la Météorologie Nationale, Niger, (1987) for Niamey, the closest synoptic station to the HAPEX-Sahel sites.

The errors in estimates may be a manifestation of inadequacies in the formulation of key model parameters, such as residence time or hydraulic conductivity, which control the rate of soil moisture depletion, and/ or infiltration capacity, which controls the rate of generation of soil moisture. It is noteworthy that the model is highly sensitive to clay content, which strongly influences both infiltration capacity and hydraulic conductivity. Furthermore, clay contents of $5 \%$ (as in the HAPEX sites) are at the limit of the validity of the 
parameterization (Lare 1992). The very large spatial variability of rainfall in the SS supersite might also introduce some errors in model estimates.

A daily version of the model was also applied to the HAPEX-Sahel region (Nicholson et al. 1996b). Those results suggested a systematic overestimation of soil moisture in the CE and SS supersites that may have been related to assumptions concerning the depth of daily exchange processes. The two models show considerable contrast with respect to the partitioning of immediate and delayed processes, particularly for evapotranspiration. Monthly results indicate that immediate evapotranspiration is about $40 \%-70 \%$ larger than delayed during the May-September season but that delayed evapotranspiration exceeds immediate during the dry out period after the end of September. In the daily model, immediate evapotranspiration exceeds delayed only during periods when precipitation (from storm rain) is high and has not been yet incorporated by plants. Consequentially, the total contribution of immediate processes is considerably smaller than in the monthly model. These results are not contradictory in that the timescales defining "immediate" are distinctly different in the two models.

The HAPEX-Sahel observations provide an excellent opportunity to test our model in the Sahel region. The results of this study give us some confidence in the model's ability to reasonably reproduce the basic hydrological exchange processes in the region. In turn, further applications of the model will extend the benefits of the observations made during the HAPEX-Sahel campaign beyond the termination of the experiment. The evapoclimatonomy model has proven to be useful in studies of water balance at the subsite and supersite scales for the various land-cover types in the HAPEX-Sahel region. Applications to other regions are feasible and would help to improve our understanding of land surface-atmosphere interaction processes in various regions of the world.

Acknowledgments. We would like to thank Dr. T. Lebel, principal investigator of the HAPEX-Sahel project, and Dr. J. D. Cooper, who have provided us with the hydrological data used in this paper. We also want to extend our thanks to the EPSAT-Niger and the AGRHYMET Center (Niamey) research teams and to the staff of the HAPEX-Sahel Information System (HSIS) in Toulouse, France. In particular, we wish to thank Shelly Thawley from the Department of Geography at the University of Maryland for providing us with access to the HAPEX-Sahel database. Support for the project was provided by NASA Grant NAGW-3101 to Florida State University and by NSF Grant ATM 9024340 .

\section{REFERENCES}

Albrecht, F., 1965: Untersuchungen des Wärme- und Wasserhaushaltes der südlichen Kontinente. Ber. Dtsch Wetterdienstes, 14, $54 \mathrm{pp}$.
Ba, M. B., R. Frouin, and S. E. Nicholson, 1995: Satellite-derived interannual variability of West African rainfall 1983-88. J. Appl. Meteor., 34, 411-431.

Brakensiek, E. L., and W. J. Rawls, 1983: Agriculture management effects on soil water processes. Part II: Green and Ampt parameters for crusting soils. Trans. Amer. Soc. Agric. Eng. 26, $1753-$ 1757.

Charney, J., 1975: Dynamics of deserts and drought in the Sahel. Quart. J. Roy. Meteor. Soc., 101, 193-202.

Direction de la Météorologie Nationale, 1987: Annuaire météorologique du Niger 1987. Republique du Niger, Ministere des Transports et du Tourisme, $100 \mathrm{pp}$.

Dorman, J. L., and P. J. Sellers, 1989: A global climatology of albedo, roughness length, and stomatal resistance for atmospheric general circulation models as represented by the Simple Biosphere Model (SiB). J. Appl. Meteor., 28, 833-855.

Entekhabi, D., 1984: Spectral analysis and stochastic modeling of streamflow using the Fourier series: The case of the Niger River. M.S. thesis, Dept. of Environmental Affairs, Clark University, $126 \mathrm{pp}$.

, I. Rodriguez-Iturbe, and R. Bras, 1992: Variability in largescale water balance with a land surface interaction. J. Climate, $\mathbf{5}, 798-813$.

FAO/UNESCO, 1971-1987: Soil Map of the World. UNESCO, Vols. II-X.

—, 1977: Africa. Vol. 6, Soil Map of the World, UNESCO, 218 pp.

Farrar, T. J., S. E. Nicholson, and A. R. Lare, 1994: The influence of soil type on the relationships between NDVI, rainfall and soil moisture in semi-arid Botswana. Part II: Relationship to soil moisture. Remote Sens. Environ, 50, 121-130.

Gardner, C. M., J. P. Bell, J. D. Cooper, M. G. Hodnett, and N. Gardner, 1991: Soil water content. Soil Analysis: Physical Methods, K. A. Smith and C. E. Mullins, Eds., 1-73.

Goutorbe, J.-P., and Coauthors, 1994: HAPEX-Sahel: A large scale observational study of land-atmosphere interaction in the semiarid-tropics. Ann. Geophys., 12, 53-64.

Henning, D., 1989: Atlas of the Surface Heat Balance of the Continents: Components and Parameters Estimated from Climatological Data. Gebrüder Borntraeger, 402 pp.

Justice, C. O., B. N. Holben, and M. Gwyne, 1986: Monitoring East African vegetation using AVHRR data. Int. J. Remote Sens., 7, $1453-1474$.

Lare, A. R., 1992: An investigation into land-surface feedback and the African drought using climatonomy modeling. Ph.D. dissertation, Florida State University, 333 pp. [Available from Dept. of Meteorology, Florida State University. Tallahassee, FL 32306].

— surface energy balance in the central Sahel. Part I: Shortwave radiation. J. Appl. Meteor., 29, 123-137.

- and - 1994: Contrasting conditions of surface water balance in wet and dry years as a possible land surface-atmosphere feedback mechanism in the West African Sahel. J. Climate, 7, 653-668.

Lebel, T. H., and L. LeBarbe, 1995: Rainfall climatology in the Central Sahel during the years 1950-1990. J. Hydrol., in press.

, H. Sauvageout, M. Hoepffner, M. Desbois, B. Guillot, and P. Hubert, 1992: Rainfall estimation in the Sahel: The EPSATNiger experiment. Hydrol. Sci. J., 37, 201-215.

_ J. D. Taupin, and LeBarbe, 1995a: Space-time fluctuations of rainfall during HAPEX-Sahel. J. Hydrol., in press.

- _ _ and M. Greard, 1995b: Rainfall monitoring: The EPSAT-Niger set-up and its use for HAPEX-Sahel. Hydrologie et Meteorologie de Meso-Echelle dans HAPEX-Sahel: Dispositif de Mesures au Sol et Premier Results, T. Lebel, Ed. ORSTOM, $43-82$.

Lettau, H. H., and K. Lettau, 1969: Shortwave radiation climatonomy. Tellus, 21, 208-222.

, and — 1975: Regional climatonomy of tundra and boreal forest in Canada. Climate of the Arctic. Proc. 29th Alaskan Sci- 
ence Conf. Fairbanks, AK, AAAS and Amer. Meteor. Soc., 209-221.

Monteny, B. A., 1993: HAPEX-Sahel 1992. Campagne de Mesures, Supersite Central Est., ORSTOM, 230 pp.

Nicholson, S. E., 1981: Rainfall and atmospheric circulation during drought periods and wetter years in West Africa. Mon. Wea. Rev., 109, 2191-2208.

_ 1986: African drought: As example of the influence of land surface properties on climate? Proc. Conf. on Parameterization of Land-Surface Characteristics, Use of Satellite Data, and First Results of the ISLSCP. Rome, Italy, European Space Agency, 405-410.

_ 1989: African drought: Characteristics, causal theories and global teleconnections. Understanding Climate Change, A. Berger, R. E. Dickinson, and J. W. Kidson, Eds., Amer. Geophys. Union, 79-100.

— and A. R. Lare, 1990: A climatonomic description of the surface energy balance in Central Sahel. Part II: The evapoclimatonomy submodel. J. Appl. Meteor., 29, 138-146.

$\longrightarrow,-$ J. A. Marengo, and P. Santos, 1996a: A revised version of Lettau's evapoclimatonomy model. J. Appl. Meteor., 35, $549-561$.

_ J. A. Marengo, J. Kim, A. R. Lare, S. Galle, Y. H. Kerr, 1996b: A daily resolution evapoclimatonomy model applied to surface water balance calculations at the HAPEX-Sahel supersites. $J$. Hydrol., in press.

Peugeot, C., and M. Esteves, 1993: Runoff generation at the plot and small catchment scale in the Central East supersite of the HAPEX-Sahel 92 experiment. Proc. Fall Meeting of the American Geophysical Union, San Francisco, CA, Amer. Geophys. Union, $232 \mathrm{pp}$

Prince, S., Y. H. Kerr, J.-P. Goutorbe, T. Lebel, A. Tinga, P. Bessemoulin, J. Brower, A. J. Dolman, E. T. Engman, J. H. C. Gash,
M. Hoepffner, P. Kabat, B. Monteny, F. Said, P. Sellers, and J. Wallace, 1995: Geographic, biologic and remote sensing aspects of the Hydrologic-Atmospheric Pilot Experiment in the Sale (HAPEX-Sahel). Int. J. Remote Sens., in press.

Rawls, W. J., and D. Brakensiek, 1989: Estimation of soil water retention and hydraulic properties. Unsaturated Flow in Hydrologic Modeling: Theory and Practice, H. J. Morel-Seytoux, Ed., Kluwer Academic Publishers, 275-300.

Saxton, K. E., W. J. Rawls, J. S. Romberger, and R. J. Papendick, 1986: Estimating generalized soil-water characteristics from texture. Soil. Sci. Soc. Amer. J., 50, 1031-1036.

Sellers, W., 1965: Physical Climatology. University of Chicago Press, $272 \mathrm{pp}$.

Serafini, Y. V., and Y. C. Sud, 1987: The time-scale of the soil hydrology using a simple water budget model. J. Climatol., 7, $585-591$.

Sivakumar, M. V. K., 1987: Climate of Niamey. Progress Rep. 1, ICRISAT Sahelian Center, Niamey, Niger, International Crops Research Institute for the Semiarid Tropics, $36 \mathrm{pp}$.

Stull, R., 1988: Boundary Layer Meteorology. Kluwer, 256 pp.

Wallace, J. S., and Coauthors, 1994: HAPEX-Sahel southern supersite report: An overview of the site and the experimental programme during the intensive observation period in 1992. Institute of Hydrology, $55 \mathrm{pp}$.

Warrilow, D., 1986: The sensitivity of UK meteorological office atmospheric general circulation model to recent changes to the parameterization of hydrology. Proc. ISLSCP Conference, Rome, Italy, European Space Agency, 143-149.

Webb, R. S., C. E. Rosenzweig, and E. R. Levine, 1991: A global data set of soil particle size properties. NASA Tech. Memo. 4286, $33 \mathrm{pp}$.

White, F., 1983: The Vegetation of Africa. UNESCO, 383 pp.

Zobler, L., 1986: A world soil file for global climate modeling. NASA Tech. Memo. 87802, 76 pp. 